${ }^{1}$ Studenckie Koło Naukowe przy Katedrze i Klinice Chorób Wewnętrznych, Diabetologii i Nefrologii Wydziału Lekarskiego

${ }^{2}$ Katedra i Klinika Chorób Wewnętrznych, Diabetologii i Nefrologii Wydziału Lekarskiego z Oddziałem Lekarsko-Dentystycznym w Zabrzu,

Śląski Uniwersytet Medyczny, Katowice

\title{
Telemedicine in response to challenges of modern diabetology
}

\section{ABSTRACT}

Due to the steadily increasing number of patients with diabetes all over the world, access to specialist diabetes care is becoming difficult, especially in rural areas. Approximately $30 \%$ of diabetic patients do not achieve the target blood glucose values, which is certainly an important problem of modern diabetology, because it translates into late vascular complications of diabetes, lower quality of life and premature death. In response to the raising demand for diabetes care, technological solutions increasing the accessibility to healthcare professionals with a concomitant reduction of costs of such care may be very useful. In a view of the above, the contribution of continuously developing widely understood information and communication technologies (ICT) to an improvement of blood glucose control in diabetic patients has been recently evaluated in research studies. Phone consultations, remote blood glucose levels monitoring and video consultations are the most commonly studied telemedical interventions. Each of them leads to an increased accessibility to specialist diabetes care. Besides clinical trials, in real patients' life there are many mobile health applications (apps) available which may be helpful in daily life diabetes management however raise concerns about regulation and approval, privacy, accuracy and safety.

Address for correspondence: dr n. med. Katarzyna Nabrdalik

Katedra i Klinika Chorób Wewnętrznych, Diabetologii i Nefrologii

ul. 3-go Maja 13-15, 41-800 Zabrze

e-mail: knabrdalik@yahoo.com

Clinical Diabetology 2016, 5, 1, 22-25

DOI: $10.5603 /$ DK.2016.0004

Received: 10.12.2015

Accepted: 20.01.2016
Contrary to cardiology, telemedical solutions in diabetology are not popular for commercial use yet, which is why patients and their physicians still have to wait for standardisation and appropriate legal regulations for telemedical interventions in diabetes care. Although as evidenced by clinical trials, such interventions translate into improved blood glucose control, lower costs of diabetes care and even a reduction of hypoglycaemia risk. (Clin Diabet 2016; 5, 1: 22-25)

Key words: telemedicine, type 1 diabetes, type 2 diabetes

\section{Introduction}

Currently, over 366 million people in the world are estimated to have diabetes, and 552 million (what translates to $9.9 \%$ of the world population) will have diabetes by 2030 [1]. Treatment of diabetes and its complications is extremely expensive and imposes a considerable economic burden on healthcare. The disease is incurable but optimal control of blood glucose level enables minimisation of the risk of complications [2]. Apparently, less than $70 \%$ of diabetic patients achieve the target blood glucose values, which indicates that effective diabetes treatment remains a challenge for modern diabetology [3]. In a view of the raising number of diabetic patients, whose life span has been increasing owing to the advancements in medicine and pharmacy, the access to specialist care becomes more and more difficult, especially among the inhabitants of rural areas. On the other hand, the more difficult access to diabetes care is partially responsible for worse metabolic control in diabetic patients and for the occurrence of diabetic complications. In response to the increasing demand for diabetes care, technological 
solutions spreading the accessibility to healthcare professionals with a concomitant reduction of costs of such care could be useful [4].

Like other life domains, also medicine could not resist the influence of the ubiquitously present internet. In the recent years, more and more so-called "e-services", including e-health, have been appearing in the world; they combine the use of the internet and other related technologies in healthcare. Initially, World Health Organization (WHO) referred to remote medical activities as medical telematics, while currently the "telemedicine" term concentrates also on remote medical education (remote teaching) apart from therapeutic aspects or "mHealth" that stands for mobile health.

Telemedicine means remote provision of health-related services with the use of telecommunication technologies such as phones or the internet. Mobile health is defined as "mobile computing, medical sensor, and communications technologies" that enhance chronic diseases beyond the traditional outpatient physician-patient encounter. Some of the services require direct involvement of patients and healthcare professionals, other only passively collect blood glucose data and transfer them to specialists for evaluation $[5,6]$.

In 2009, "The Economist" reported that possession of a mobile phone had contributed to a greater and faster change in life of a larger number of people than any other technology. In many countries in Europe almost 100 per cent of the population possesses a mobile phone. Moreover, recently also smartphones and tablets have been contributing to a change in lifestyle, work and play. However, legal, social and political regulations do not keep up with those changes, although the decision-makers are aware of the benefit potential and draw upon those benefits. The healthcare system is no exception and the use of modern technologies also can bring huge benefits [7]. In an article from 2014, members of the International Diabetes Federation (IDF) emphasise the fact that patients with diabetes require constant discipline, and wide access to specialist information about their disease is beneficial. Diabetic patients contact a diabetologist for 10 hours in a year on average, and for the remaining amount of time the patients are left on their own. However, they usually have a mobile phone with them which is currently used not only for phone communication but is often an ongoing source of information, entertainment, education, social meetings and other services. Introducing such a tool into the healthcare system could improve access to medical knowledge and care [7]. The present article presents selected telemedical or mHealth tools which may find their place in diabetology care.

\section{Teleconferences}

In a view of the insufficient number of specialist physicians, especially in rural areas, and the increasing prevalence of type 2 diabetes, medical video consultations based on the video conference principle may constitute a potential solution to geographical barriers limiting access to specialist medical care. There were some studies trying to use various of teleconference models, but the data on the effectiveness of this approach measured by a significant reduction of the $\mathrm{HbA}_{1 \mathrm{c}}$ value are insufficient. These studies either did not take into account $\mathrm{HbA}_{1 c}$ values or did not include the assessment of a control group or demonstrated only a very small difference in $\mathrm{HbA}_{1 \mathrm{c}}$ reduction $(0.32 \%)$ [8-11]. Additionally, often no physician but only an educator participated in the research. Only as recently as in 2014, the TREAT (Telemedicine for Reach, Education, Access, and Treatment) study was published in Diabetes Care. The study demonstrated a significant improvement in metabolic control of diabetes owing to the use of teleconsultations. That study assessed the efficacy of combining video consultations conducted by an endocrinologist from an urban centre collaborating with a local diabetes educator in reducing $\mathrm{HbA}_{1 \mathrm{c}}$ in persons inhabiting rural areas. Patients with type 2 diabetes with poor metabolic control $\left(\mathrm{HbA}_{1 \mathrm{c}}>7.0 \%\right)$, who had difficulty in access to specialist medical care because of their place of residence, were enrolled in the study. Thanks to a diabetes nurse (educator), patients attended a video consultation every three months for half a year. $\mathrm{HbA}_{1 c}$ was measured at 3 and 6 months after the onset of treatment and compared with the control group of persons who received standard treatment within the framework of routine primary medical care. The persons receiving telemedical care were demonstrated to have better metabolic control of diabetes in comparison with the persons receiving standard care, after adjustment for insulin use, sex, age, BMI and duration of diabetes. In $84 \%$ of study subjects, therapy had to be intensified (by initiating insulin therapy, adding another insulin formulation, or increasing the total daily insulin dose or oral agents). Ninety-three per cent of the subjects adhered to selfmonitoring of blood glucose recommendations. The mean incidence of hypoglycaemia was $1.7 / 30$ days; mild cases were a majority and severe hypoglycaemia was rare, which indicates the safety of this method of medical consultations [12].

\section{Remote blood glucose monitoring and insulin dose titration}

Self-monitoring of blood glucose by the patient is an essential factor that enables diabetic patients 
to obtain good metabolic control of their disease. Up to not so long ago, patients had to keep the so-called blood glucose self-monitoring diaries in the paper form, and currently the advancement in glucose meters and remote technologies has made it possible to record measurements made on glucose meters in the electronic form, and have them analysed by a diabetologist during or before the visit at the Diabetes Clinic. Regardless of diabetes treatment with oral medicines or insulin, patients conducting self-monitoring of blood glucose were demonstrated to obtain lower $\mathrm{HbA}_{1 \mathrm{c}}$ values [13].

Insulin treated patients need insulin adjustment according to their blood glucose levels but face-to-face visits are time consuming and associated with absence form work for occupationally active persons what could be troublesome especially for those of low socioeconomic status. One of the randomised clinical trials initiated in 2013 including 61 low income, urban (New York) patients with type 2 diabetes aimed to evaluate effectiveness of remote advice of how to titrate basal insulin throughout a short messages services (SMS) text messaging and phone calls a well as cost savings and patients satisfaction of this intervention. It was proven that significantly greater proportion of patients in the interventional arm reached their optimal basal insulin dose than patient in the usual care arm. Additionally the intervention was feasible and cot saving in meaning of patients time who could titrate their insulin dose without multiple clinic visits [14].

\section{Applications in mobile devices}

In 2011, the TELEDIAB-1 study was published in Diabetes Care. The study demonstrated that the use of the Diabeo system (a smartphone coupled to a website), in which the insulin dose was proposed automatically and results were controlled at a teleconsultation in patients with type 1 diabetes, led to a reduction of $\mathrm{HbA}_{1 \mathrm{c}}$ values by $0.9 \%$ within half a year in comparison with a control group receiving standard treatment [15]. A post hoc analysis of that study was published in 2014 and confirmed usefulness of the system however a bigger study involving 700 patients from 100 diabetes centres for a period of 2 years is planned in order to obtain reimbursable status for Diabeo system from French National Health Insurance system [16]. Waki et al. studied an application named DialBetics in which one of the examined functions was food recording with the use of a multimedia food record, FoodLog. A dietitian who analysed obtained information advised the diabetic patient about diet modifications. The meal-photo function providing patients with real-time support for diet modification has been shown to be an effective and convenient tool [17].
A very important element of remote monitoring of blood glucose in patients with type 1 diabetes is reducing the incidence of hypoglycaemia episodes, which are often a barrier in attaining diabetes treatment targets [17-19]. An interesting solution has been proposed by Rossi et al. who studied smartphone application named "Diabetes Interactive Diary" (DID) which is a carbohydrate/bolus calculator promoting the patient-physician communication via SMS among 127 patients not previously educated on carbohydrate counting who were randomly assessed to a DID group or traditional education group. 6 months of application usage resulted in reduced risk of moderate/severe hypoglycaemia and improved quality of life [18].

Currently, there are many medical applications freely available for mobile devices that enable the control of self-measurements of blood glucose level but they are not synchronised with other devices or IT systems nor standardised. Therefore, international standardisation organisations such as IEEE 11073 PHD WG (Personal Health Working GROUP) or Health Level Seven (HL7) created ISO/IEEE 11073 and the Continuity of Care Document (CCD), to ensure compatibility between personal medical devices and the medical information system and thus to reduce healthcare costs and concomitantly increase the quality of treatment. Personal data from glucose meters should be generated in the form of standard reports which can be sent between medical centres. It is necessary to create an application connected to a glucose meter and to conduct large-scale studies evaluating the usefulness of such applications for patients and healthcare professionals with a view to improve blood glucose control [20].

\section{Summary}

In the world, the number of patients with type 1 and type 2 diabetes has been steadily increasing, which has made access to a diabetes specialist and education quite frequently limited. Both the healthcare system and the patients themselves are to blame for this situation. Firstly, not in all regions of the countries there is a sufficient number of diabetologists. Secondly, at least in Poland, only limited number of patients envisaged by the National Health Fund can be admitted to diabetes out patient clinics. Thirdly, the limited possibility of undergoing a diabetes consultation is associated with the patients themselves and their lack of time or difficulties with travelling to a physician because due to inability to be absent from work or due to physical disability to move.

Poorly managed diabetes, and thus chronic hyperglycaemia, inevitably leads to vascular complications of diabetes and consequentially to disabilities and pre- 
mature deaths, most commonly due to cardiovascular causes. Many of the patients do not achieve adequate metabolic control of the disease, which is frequently associated with the lack of diabetes education or access to diabetes consultations. No even the most modern medicines or medical devices (glucose meters or insulin pumps) will contribute to improved metabolic control of diabetes without proper diabetes education and supervision by the diabetologist conducting the treatment.

The novel options of supervising the treatment of diabetic patients with the use of telemedical or so called mHealth methods, without the need for personal visits at the diabetes clinic, and of obtaining diabetes education on-line (e-education) make it possible to improve blood glucose control and quality of life of a large number of young diabetic patients without adequate metabolic control so far.

In the era of smartphones and general internet access popularisation of telemedical solutions may in the future become a method to improve glycaemic control of persons who have difficult access to diabetologists because of their place of residence, type of work or motor disabilities, making it difficult for them to personally visit a physician at a Diabetes Clinic. Patients from rural areas often have to cover distances of many kilometres to undergo a consultation, which is associated with higher costs for the patients and with absenteeism from work.

On the other hand, besides clinical trials where telemedical solutions are widely used, international diabetes societies currently do not recommend the use of diabetic telecare in the daily life due to the lack of authorisation and standardisation of telemedical services. Most applications that appear in the market are not accepted by the Food and Drug Administration because they are non-compliant with the guidelines issued in 2011 by FDA. It should also be borne in mind that smartphone applications and other forms of telemedicine will not replace an assessment by a clinician and may only be a helpful tool in diabetes control.

\section{Disclosure: none}

\section{REFERENCES}

1. Whiting DR, Guariguata L, Weil C, Shaw J. IDF diabetes atlas: global estimates of the prevalence of diabetes for 2011 and 2030. Diabetes Res Clin Pract 2011; 94: 311-321.

2. The effect of intensive treatment of diabetes on the development and progression of long-term complications in insulin-dependent diabetes mellitus. The Diabetes Control and Complications Trial Research Group. N Engl J Med 1993; 329: 977-986.
3. Bouma M, Dekker JH, van Eijk JT, Schellevis FG, Kriegsman DM, Heine RJ. Metabolic control and morbidity of type 2 diabetic patients in a general practice network. Fam Pract 1999; 16: 402-406.

4. Charles BL. Telemedicine can lower costs and improve access. Healthc Financ Manage 2000; 54: 66-69.

5. Estrin D, Sim I. Health care delivery. Open mHealth architecture: an engine for health care innovation. Science 2010; 330: 759-760.

6. Eng DS, Lee JM. The promise and peril of mobile health applications for diabetes and endocrinology. Pediatr Diabetes 2013; 14 : 231-238. PubMed PMID: 23627878.

7. How mobile health can help tackle the diabetes epidemic and strengthen health systems: International Diabetes Federation (IDF) response to the public consultation on the European Commission's Green Paper on mobile health. Diabetes Res Clin Pract 2014: 105: 271-272.

8. Toledo FG, Triola A, Ruppert K, Siminerio LM. Telemedicine consultations: an alternative model to increase access to diabetes specialist care in underserved rural communities. JMIR Res Protoc 2012; 1: e14. PubMed PMID: 23612044.

9. Ciemins E, Coon P, Peck R, Holloway B, Min SJ. Using telehealth to provide diabetes care to patients in rural Montana: findings from the promoting realistic individual self-management program. Telemed J E Health 2011; 17: 596-602.

10. Nyenwe EA, Ashby S, Tidwell J, Nouer SS, Kitabchi AE. Improving Diabetes Care via Telemedicine: Lessons From the Addressing Diabetes in Tennessee (ADT) Project. Diabetes Care 2011; 34: e34.

11. Shea $S$, Weinstock RS, Starren J et al. A randomized trial comparing telemedicine case management with usual care in older, ethnically diverse, medically underserved patients with diabetes mellitus. J Am Med Inform Assoc 2006; 13: 40-51.

12. Toledo FG, Ruppert K, Huber KA, Siminerio LM. Efficacy of the Telemedicine for Reach, Education, Access, and Treatment (TREAT) model for diabetes care. Diabetes Care 2014; 37: e179-e180.

13. Cameron C, Coyle D, Ur E, Klarenbach S. Cost-effectiveness of self-monitoring of blood glucose in patients with type 2 diabetes mellitus managed without insulin. CMAJ 2010; 182: 28-34. PubMed PMID: 20026626.

14. Levy N, Moynihan V, Nilo A et al. The Mobile Insulin Titration Intervention (MITI) for Insulin Adjustment in an Urban, Low-Income Population: Randomized Controlled Trial. J Med Internet Res 2015; 17: e180

15. Charpentier G, Benhamou PY, Dardari D et al. The Diabeo software enabling individualized insulin dose adjustments combined with telemedicine support improves $\mathrm{HbA} 1 \mathrm{c}$ in poorly controlled type 1 diabetic patients: a 6-month, randomized, open-label, parallelgroup, multicenter trial (TeleDiab 1 Study). Diabetes Care 2011; 34: 533-539.

16. Franc $\mathrm{S}$, Borot $\mathrm{S}$, Ronsin $\mathrm{O}$ et al. Telemedicine and type 1 diabetes: is technology per se sufficient to improve glycaemic control? Diabetes Metab 2014; 40: 61-66.

17. Waki K, Aizawa K, Kato S et al. DialBetics With a Multimedia Food Recording Tool, FoodLog: Smartphone-Based Self-Management for Type 2 Diabetes. J Diabetes Sci Technol 2015; 9: 534-540. PubMed PMID: 25883164.

18. Rossi MC, Nicolucci A, Lucisano G et al. Impact of the "Diabetes Interactive Diary" telemedicine system on metabolic control, risk of hypoglycemia, and quality of life: a randomized clinical trial in type 1 diabetes. Diabetes Technol Ther 2013; 15: 670-679.

19. Choi YS, Cucura J, Jain R, Berry-Caban C. Telemedicine in US Army soldiers with type 1 diabetes. J Telemed Telecare 2015; 21: 392-395.

20. Park HS, Cho H, Kim HS. Development of Cell Phone Application for Blood Glucose Self-Monitoring Based on ISO/IEEE 11073 and HL7 CCD. Healthc Inform Res 2015; 21: 83-94. PubMed PMID: 25995960. 